\title{
Transient Global Amnesia with Bilateral Hippocampal Findings in
}

\section{Magnetic Resonance Imaging.}

Sonia P. Rodriguez ${ }^{1 *}$, Alfredo Fernandez de Castro ${ }^{2}$, and Carlos Enrique Trillos Peña ${ }^{3}$.

${ }^{1}$ Neuroradiologist, Clínica de Marly, Bogotá, Colombia.

${ }^{2}$ Neuroradiologist, Hospital Universitario Mayor- Mederí, Bogotá, Colombia.

${ }^{3}$ Epidemiologist, Universidad del Rosario, Bogotá, Colombia.

*Corresponding Author: Sonia P. Rodriguez, Neuroradiologist, Clínica de Marly, Bogotá, Colombia.

E-mail: rocosopi@gmail.com

Received date: September 22, 2020; Accepted date: October 02, 2020; Published date: October $09,2020$.

Citation: Sonia P. Rodriguez, Alfredo Fernandez de Castro, Carlos Enrique Trillos Peña (2020), Transient global amnesia with bilateral hippocampal findings in magnetic resonance imaging. J. Brain and Neurological Disorders, 3(1): DOI: 10.31579/2642-973X/011.

Copyright: () 2020 Sonia P. Rodriguez. This is an open-access article distributed under the terms of The Creative Commons Attribution License, which permits unrestricted use, distribution, and reproduction in any medium, provided the original author and source are credited.

\section{Abstract}

Transient global amnesia (TGA) is an unusual neurological syndrome of unknown etiology that affects individuals between 50 and 75 years old. We describe the case of a 61-year-old woman, who experienced an episode of two hours of anterograde amnesia. The event had an acute onset and was observed by a reliable witness. It lacked motor or sensory symptoms, compromised consciousness, or personal identity. A brain magnetic resonance was performed 22 hours after the onset of symptoms depicting foci of restricted diffusion in both hippocampi. Taking into account clinical and imaging findings, the diagnosis of transient global amnesia was made.

Keywords: amnesia, transient global; amnesia, anterograde; magnetic resonance imaging, diffusion magnetic resonance imaging, hippocampus

\section{Case History:}

A 61-year-old Latin-American woman with a history of dyslipidemia and gastritis consulted the emergency room for an episode of anterograde amnesia. Symptoms began at 5:00 A.M. and lasted 2 hours. Witnesses reported that the patient exhibited no hallucinations or disturbances in behavior, executive functions, motor functions, working memory, or language during the event. After the event, the patient experienced headache, dizziness, nausea, and an inability to remember the episode. No trigger events were identified, and that morning, the patient did not consume any medicine.

At admission, her physical and mental explorations were normal and stable during a 2-day hospitalization period. Blood pressure remained within the normal range. Blood was tested for serum glucose, glycosylated hemoglobin, thyroid-stimulating hormone, and lipid panel levels. High levels of low-density lipoprotein (199 mg/dL) and pre-

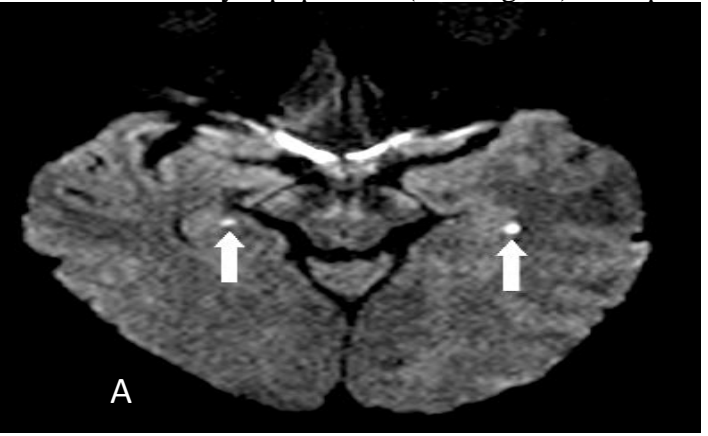

diabetic levels of glycosylated hemoglobin (5.9\%) were found. Other blood test results were within the normal range. Electrocardiogram, transthoracic echocardiogram, carotid Doppler ultrasonography, and brain-computed tomography revealed normal results.

Brain magnetic resonance was performed 22 hours after symptom onset, revealing two foci of restricted diffusion on both hippocampi. The other sequences were normal (Figure 1 and 2). Taking into account clinical and imaging findings, transient global amnesia was diagnosed. The differential diagnosis considered in this case were bilateral lacunar stroke and transient epileptic amnesia.

After discharge, the patient was treated with atorvastatin for dyslipidemia and a strict diet was ordered. No medications were prescribed for transient global amnesia. A close follow-up was conducted for 10 months, without new symptoms. General recommendations were followed by the patient and their family.

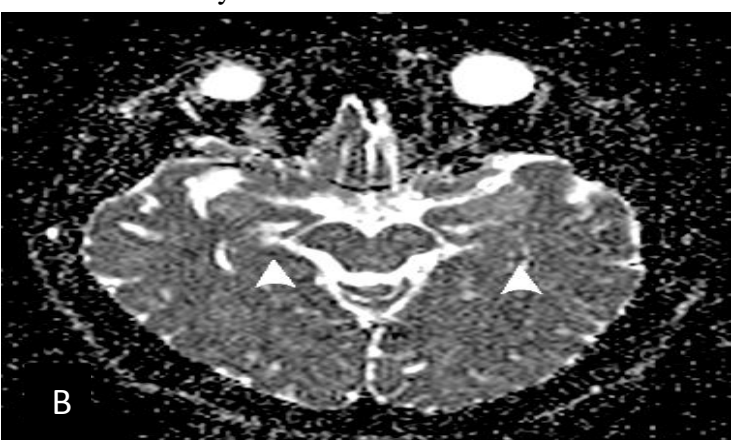

Figure 1: Axial brain MRI scan in a 61-year-old woman with an episode of two hours of anterograde amnesia that resolved completely. (A) diffusion weighted images (DWI) and (B) complementary apparent diffusion coefficient (ADC) map, depict two foci of restricted diffusion on both hippocampi, with high signal intensity in DWI (arrows) and low signal intensity in the ADC map (arrowheads). 

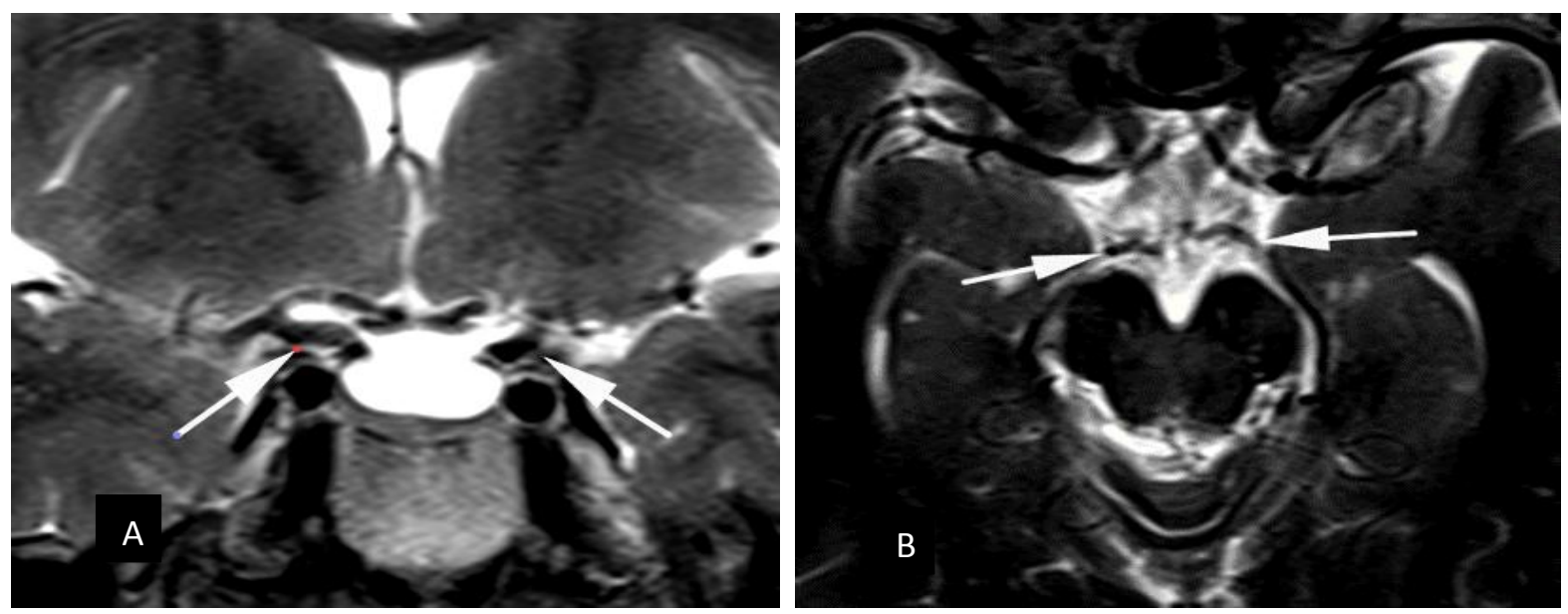

Figure 2: Coronal and axial T2 weighted MR images in the same patient show expected flow voids that imply permeability in A: the supraclinoid and terminal segments of the internal carotid artery, and (B) in the first segment of the posterior cerebral arteries.

\section{Discussion}

Transient global amnesia (TGA) is an unusual neurological syndrome with annual incidence rates between 3 and 10 per 100,000 inhabitants, affecting individuals between 50 and 75 years old. This syndrome is characterized by sudden onset of anterograde amnesia accompanied by mild vagal symptoms including headache, nausea, dizziness, sweating, and slight tremor, resolving in less than 24 hours, without other cognitive or motor impairments $[1,2]$

Transient hippocampal focal alterations are the underlying cause of the characteristic symptoms of TGA, but its etiology and pathophysiology remain contentious. Several possible causes of disruption in local metabolism have been suggested, including hypoxia due to arterial spasm or venous congestion, focal transient ischemia, aberrant expression of receptors and neurotransmitters, or focal depolarization in susceptible subjects. Between $15 \%-50 \%$ of patients describe a triggering circumstance such as stress, abrupt temperature changes, migraine, or intense Valsalva maneuver. Associations with high blood pressure, dyslipidemia, smoking, alcohol, and migraine have been previously suggested [3-7].

Because of the anterograde amnesia is experienced by patients, a reliable witness is needed for accurate clinical diagnosis. Magnetic resonance (MR) is the only diagnostic tool reported to show positive and characteristic results for TGA. MR diffusion-weighted images (DWI) and complementary apparent diffusion coefficient (ADC) maps are used to identify cytotoxic edema in the region of interest. In TGA patients, these sequences exhibit small foci of hippocampal restricted diffusion [8-13].

It has been reported that MR performed between 48-72 hours after the onset of symptoms with continuous thin-slice acquisition revealed the characteristic hippocampal findings in $50 \%-85 \%$ of patients. One hippocampal focus is found in $46-69 \%$ of patients and bilateral foci in 31$50 \%$. If bilateral hippocampal characteristic lesions are associated with an appropriate clinical history and normal neurological exam results after the event, TGA should not be excluded [8, 11, 14-16].

To exclude other diagnoses with a high degree of confidence when there is doubt, MRI and electroencephalography should be performed within an appropriate timeframe. If an accurate diagnosis is accomplished, the patient and their family can be instructed about the management of probable future events. The prognosis for TGA is generally good, so no drug is prescribed, and patients are instructed with diet and exercise. Follow up studies have reported an incidence of ischemic cerebrovascular disease similar to the general population $(5 \%-7 \%)$, and no association with dementia [17-20].

Regarding the differential diagnoses, hippocampal isolated bilateral infarct incidence is very low $(0.04 \%)$. Patients with anterior hippocampal infarcts report reduced wakefulness, hallucinations, memory deficits, motor sequence learning deficits, and seizures, symptoms that last more than 24 hours. In MR restricted diffusion can involve the entire hippocampus, the lateral part, the dorsal section, and less frequently, a small focus in his lateral segment can be found [21, 22].

Transient epileptic amnesia is a subtype of temporal lobe epilepsy that develops in the seventh decade. It produces episodes of transient anterograde amnesia without motor symptoms. Episodes are triggered during the transition between sleep and waking in $70 \%$ of patients, last 1 hour on average, and can coexist with automatism, olfactory hallucinations, and episodes of stupor. Electroencephalogram exhibit epileptiform patterns, focal slow wave changes, or no abnormalities. Brain MR is normal after the event [23, 24].

\section{Conclusion}

TGA is an unusual neurological syndrome that should be carefully considered in the older adult population. MR provides a highly accurate diagnostic tool if appropriately performed by experts. AGT diagnosis should not be ruled out if bilateral MRI hippocampal restriction foci are found in patients with an appropriate clinical history. If an accurate diagnosis is obtained, the patient and their family can be reassured by the prognosis and instructed about the management of probable future events.

Conflict of interest: The authors have no conflicts of interest

Thanks Note: We thank Benjamin Knight, MSc. from Edanz Group (www.edanzediting.com/ac) for editing a draft of this manuscript.

\section{References:}

1. Brigo F, Lochner P, Tezzon F, Nardone R. (2014). Incidence of transient global amnesia in Merano, province of Bolzano, Italy. Acta Neurol Belg; 114(4):293-296.

2. Hodges JR, Warlow CP (1990). Syndromes of transient amnesia: Towards a classification. A study of 153 cases. J Neurol Neurosurg Psychiatry; 53(10):834-843.

3. Pantoni L, Lamassa M, Inzitari D (2000). Transient global amnesia: A review emphasizing pathogenic aspects. Acta Neurologica Scandinavica; 102(5):275-283. 
4. Sancesario G, Esposito Z, Mozzi AF, Sancesario GM, Martorana A, Giordano A, et al (2013). Transient global amnesia: Linked to a systemic disorder of amino acid catabolism. Vol. 260, Journal of Neurology; 1429-1432.

5. Lewis SL (1998). Aetiology of transient global amnesia. Lancet; 397-399.

6. Himeno T, Kuriyama M, Takemaru M, Kanaya Y, Shiga Y, Takeshima S, et al (2017). Vascular Risk Factors and Internal Jugular Venous Flow in Transient Global Amnesia: A Study of 165 Japanese Patients. J Stroke Cerebrovasc Dis; 26(10):22722278.

7. Döhring J, Schmuck A, Bartsch T (2014). Stress-related factors in the emergence of transient global amnesia with hippocampal lesions. Front Behav Neurosci; 8(287).

8. Scheel M, Malkowsky C, Klingebiel R, Schreiber SJ, Bohner G (2012). Magnetic resonance imaging in transient global amnesia: Lessons learned from 198 cases. Clin Neuroradiol; 22(4):335340.

9. Kim J, Kwon Y, Yang Y, Jang IM, Chang Y, Park YH, et al (2014). Clinical experience of modified diffusion-weighted imaging protocol for lesion detection in transient global amnesia: An 8-year large-scale clinical study. J Neuroimaging; 24(4):331337.

10. Sedlaczek OL, Hirsch JG, Grips E, Peters CNA, Gass A, Wöhrle J, et al (2004). Detection of delayed focal MR changes in the lateral hippocampus in transient global amnesia. Neurology; 62(12):2165-2170.

11. Choi BS, Kim JH, Jung C, Kim SY (2012). High-resolution diffusion-weighted imaging increases lesion detectability in patients with transient global amnesia. Am J Neuroradiol; 33(9):1771-1774.

12. Ahn S, Kim W, Lee YS, Kim WY, Lee JH, Oh BJ, et al (2011). Transient global amnesia: Seven years of experience with diffusion-weighted imaging in an emergency department. Eur Neurol; 65(3):123-128.

13. Alberici E, Pichiecchio A, Caverzasi E, Farina LM, Persico A, Cavallini A, et al (2008). Transient global amnesia: Hippocampal magnetic resonance imaging abnormalities. Funct Neurol; 23(3):149-152.
14. Weon YC, Kim JH, Lee JS, Kim SY (2008). Optimal diffusionweighted imaging protocol for lesion detection in transient global amnesia. Am J Neuroradiol; 29(7):1324-1328.

15. Toledo M, Pujadas F, Grivé E, Álvarez-Sabin J, Quintana M, Rovira A (2008). Lack of evidence for arterial ischemia in transient global amnesia. Stroke; 39(2):476-479.

16. Ryoo I, Kim JH, Kim SY, Choi BS, Jung C, Hwang S Il (2012). Lesion detectability on diffusion-weighted imaging in transient global amnesia: The influence of imaging timing and magnetic field strength. Neuroradiology; 54(4):329-334.

17. Pantoni L, Bertini E, Lamassa M, Pracucci G, Inzitari D (2005). Clinical features, risk factors, and prognosis in transient global amnesia: A follow-up study. Eur J Neurol; 12(5):350-356.

18. Chen ST, Tang LM, Hsu WC, Lee TH, Ro LS, Wu YR (1999). Clinical features, vascular risk factors, and prognosis for transient global amnesia in Chinese patients. J Stroke Cerebrovasc Dis; 8(5):295-299.

19. Arena JE, Brown RD, Mandrekar J, Rabinstein AA (2017). Long-Term Outcome in Patients With Transient Global Amnesia: A Population-Based Study. Mayo Clin Proc; 92(3):399-405.

20. Mangla A, Navi BB, Layton K, Kamel H (2014). Transient global amnesia and the risk of ischemic stroke. Stroke; 45(2):389-393.

21. Kumral E, Deveci EE, Erdolan CE, Enüstün C (2015). Isolated hippocampal infarcts: Vascular and neuropsychological findings. J Neurol Sci; 356(1-2):83-89.

22. Szabo K, Förster A, Jäger T, Kern R, Griebe M, Hennerici MG, et al (2009). Hippocampal lesion patterns in acute posterior cerebral artery stroke: Clinical and MRI findings. Stroke; 40(6):2042-2045.

23. Sellal F (2006). Transient amnesia in the ederly. Psychol Neuropsychiatr du Vieil; 4(1):31-38.

24. Butler CR, Zeman AZ (2008). Recent insights into the impairment of memory in epilepsy: Transient epileptic amnesia, accelerated long-term forgetting and remote memory impairment. Brain; 2243-2263.
This work is licensed under Creative Commons Attribution 4.0 License

To Submit Your Article Click Here: Submit Article

DOI: $10.31579 / 2642-973 X / 011$
Ready to submit your research? Choose Auctores and benefit from:

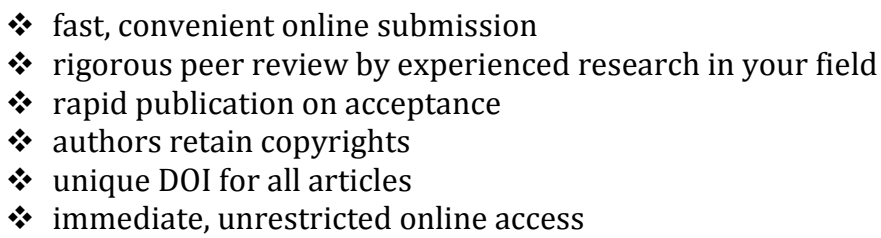

At Auctores, research is always in progress.

Learn more www.auctoresonline.org/journals/brain-andneurological-disorders- 